\title{
Secondary phases associated with diamonds in eclogites from the Udachnaya kimberlite pipe: implications for diamond genesis
}

\author{
Spetsius, Z V. ${ }^{1}$, and Griffin, B. J. ${ }^{2}$
}

1. Institute of Diamond Industry, Mirny, Yakutia, 678170, Russia

2. Centre for Microscopy and Microanalysis, The University of Western Australia, Nedlands, WA, Australia 6907

\section{Introduction}

Our understanding of diamond formation in kimberlites and diamond growth in the upper mantle still remains nebulous. Isotopic investigations of peridotitic garnet inclusions in diamonds from South Africa were interpreted to reflect diamond growth in the Archean $(\sim 3.2 \mathrm{Ga}$ ago), whereas a similar investigation of the eclogitic garnet and omphacite inclusions suggested that these are considerably younger, and may have even formed close to the time of kimberlite eruption (Richardson et al., 1993). In rare instances, diamonds extracted from mantle xenoliths contain silicate inclusions whose composition can be compared to minerals in the host xenolith in order to constrain the history both of the diamond and rock in the upper mantle. The differences in trace element abundance between included in diamonds and rockforming minerals, have been interpreted as being due to metasomatic enrichment of the rock after diamond growth (Ireland et al., 1994) or depletion of the rock by partial melting (Taylor et al., 1996). In both cases, it is clear that the inclusions record the complicated history both of the diamond and rock overprinted by later events. Additionally, there are some petrographic and other data for a late and multistage formation of diamonds in eclogite xenoliths that most probably is connected with processes of partial melting and mantle metasomatism (Spetsius, 1995).

\section{Samples and Methodology}

Although the diamondiferous xenoliths from kimberlites are investigated most data are from the rocks or the diamonds separately. We have used a general approach to characterizing the conditions of diamond formation based on studying diamonds in situ in xenoliths. In order to evaluate the relationship of diamond formation with metasomatic processes 15 samples of diamondiferous eclogites from kimberlite pipe Udachnaya have been investigated. Most xenoliths were bimineral eclogites of ferrous and magnesian series, two samples of Gt-pyroxenite and three were Ky-eclogites. Samples were sawn in to slabs containing exposed diamonds and polished. One or more polished sections and plates were made from each samples. After that the rock-forming garnet and clinopyroxene were analysed together with a range of secondary phases surrounding the diamond. They were imaged and analysed using a JEOL 6400 SEM with quantitative EDS at the Centre for Microscopy and Microanalysis of the University of Western Australia.

\section{Results}

The rock-forming garnets have a wide variation in $\mathrm{Ca}, \mathrm{Mg}$ and $\mathrm{Fe}$ content, dependent on the type of eclogites. Primary clinopyroxenes have a wide variations in $\mathrm{Na} 2 \mathrm{O}$ and $\mathrm{CaO}$. In some samples clinopyroxene is absent or totally replaced by secondary phases. Three different association of secondary minerals or stages of metasomatic processes and partial melting have been distinguished in the phases surrounding diamond. The first stage is fixed partial melting of primary clinopyroxene and replacement of omphacite by less sodium pyroxene and glass (Fig.1a). We call such process amorphitization. In rare cases some grains of garnets have also undergone such amorphitization . The second stage of partial melting is displayed by growth of a more aluminous pyroxene, spinel, phlogopite, plagioclase, and occasionally amphibole (Fig.1b). In some cases between these phases a high sodium pyroxene $(\mathrm{Na} 2 \mathrm{O} \sim 10 \mathrm{wt} \%$, Fig. 1c) is present, but in comparison with primary omphacite this pyroxene contain less $\mathrm{Al}$ and $\mathrm{Ca}$ and high content of $\mathrm{Fe}$ and corresponds to an aegerine component. Additional phases including carbonate, apatite, sulfide and others are abundant in some xenoliths especially in veins, but mostly they resemble a late stage of alteration (including part of sulfides) and probably are connected with interaction of protokimberlite fluids. 


\section{Discussion}

The recalculation of temperature of equilibration of rockforming garnets and omphacites investigated samples using a standard geothermometer $(\mathrm{Ai}, 1995)$ gives the temperatures of formation of eclogites in the range 1100-1400 deg C. Secondary pyroxenes of different associations, assumed to be in equilibrium with primary garnet, suggest the T-conditions of first stage of partial melting to be 1200$1000 \mathrm{deg} \mathrm{C}$ and the variable data for the second stage is mostly near $1000 \mathrm{deg} \mathrm{C}$. It is possible to state that partial melting processes took place under a range of T-conditions. It is clear that the processes of metasomatism and partial melting must include a fluid agent. The high content of K2O in glasses and the amorphozed primary omphacite and between minerals of partial melting products indicate considerable fluid interaction. This is confirmed by a rather widespread distribution of phlogopite, eg occurring with crystallized minerals of partial melting products and sometimes between phases within diamonds. Much data thus suggest that fluids play an important role in initiating the partial melting of eclogites and perhaps the metasomatic growth of diamonds. As was shown (Spetsius, 1995) crystals of diamonds in most mantle xenoliths are usually found between grains of primary minerals and usually are surrounded by rims of secondary minerals (Fig.1). Sometimes diamonds occur in altered clinopyroxene, where they probably grow simultaneously with this replacement. In some xenoliths diamonds on polished surface of samples are filled by secondary minerals which looks like inclusions. The crystals of diamonds can have unusual forms of growth, eg as a hopper crystals which contain inside partially melted and replaced clynopyroxenes (Fig. ld). Some diamonds have a rather obvious features of skeleton growth and they include a secondary pyroxene as inclusions or secondary phases fill some cracks. Additionally, there are present such forms of crystals which looks like coated and caselike diamonds. These features and other petrographic evidences suggest that some diamonds in eclogites grew simultaneously with the metasomatic minerals. They have formed in non-equilibrium metastable conditions most probably by an abnormal mechanism. The diamonds were grown in a melt rich in fluid or probably in some cases have crystallized from fluid. Such conditions may be realized by partial melting of eclogite xenoliths. Complex forms, the fine structures and zonality of crystals observed by cathodoluminescence of most diamonds (Fig.1) confirm their multistage formation in the eclogite xenoliths on different stages of metasomatism. Metasomatism occur under a broad spectrum of PT-conditions, and with a range of chemistries of both the original rocks and metasomatic fluids/vapors.

\section{Conclusion}

The special preparation of plates from xenoliths with diamonds in situ has allowed the collection of valuable data about distribution of diamonds in eclogites and their environment. Petrographic and mineralogic observations strongly suggest (intimate) that diamonds can grow during different stages of metasomatism and partial melting and this is further demonstrated by the multistage formation of diamonds in eclogites. Mineral compositions of different secondary phases and comparison with experimental data suggest that these metasomatic and partial melting events took place at decreasing pressure and different fluctuating PT-conditions, usually less than the temperatures of equilibration of rockforming minerals.

\section{References}

Ireland, T.R., Rudnick, R.L., Spetsius, Z.V., 1994, Trace elements in diamondinclusions from eclogites reveal link to Archean granites: Earth andPlanetary Science Letters, v.128, p.199-213. Ai , 1994, Garnet-pyroxene geothermometry, Contrib. Min. Pet. 115, p467-473.

Richardson, S.H., Harris, J. W., and Garney, J. J., 1993, Three generations of diamonds from old continental mantle: Nature, v.366, p.256.-258.

Spetsius, Z. V., 1995b, Diamondiferous eclogites from Yakutia: Evidence for a late and multistage formation of diamonds: 6th IKC Abstracts, Novosibirsk, p.572-574.

Taylor, L. A., Snyder, G. A., Crozaz, G., Sobolev, V. N., Yefimova, E. S., and Sobolev, N.V., 1996, Eclogitic Inclusions in diamonds: Evidence of complex mantle processes over time: Earth and Planetary Science letters, v.142, p.535-55 

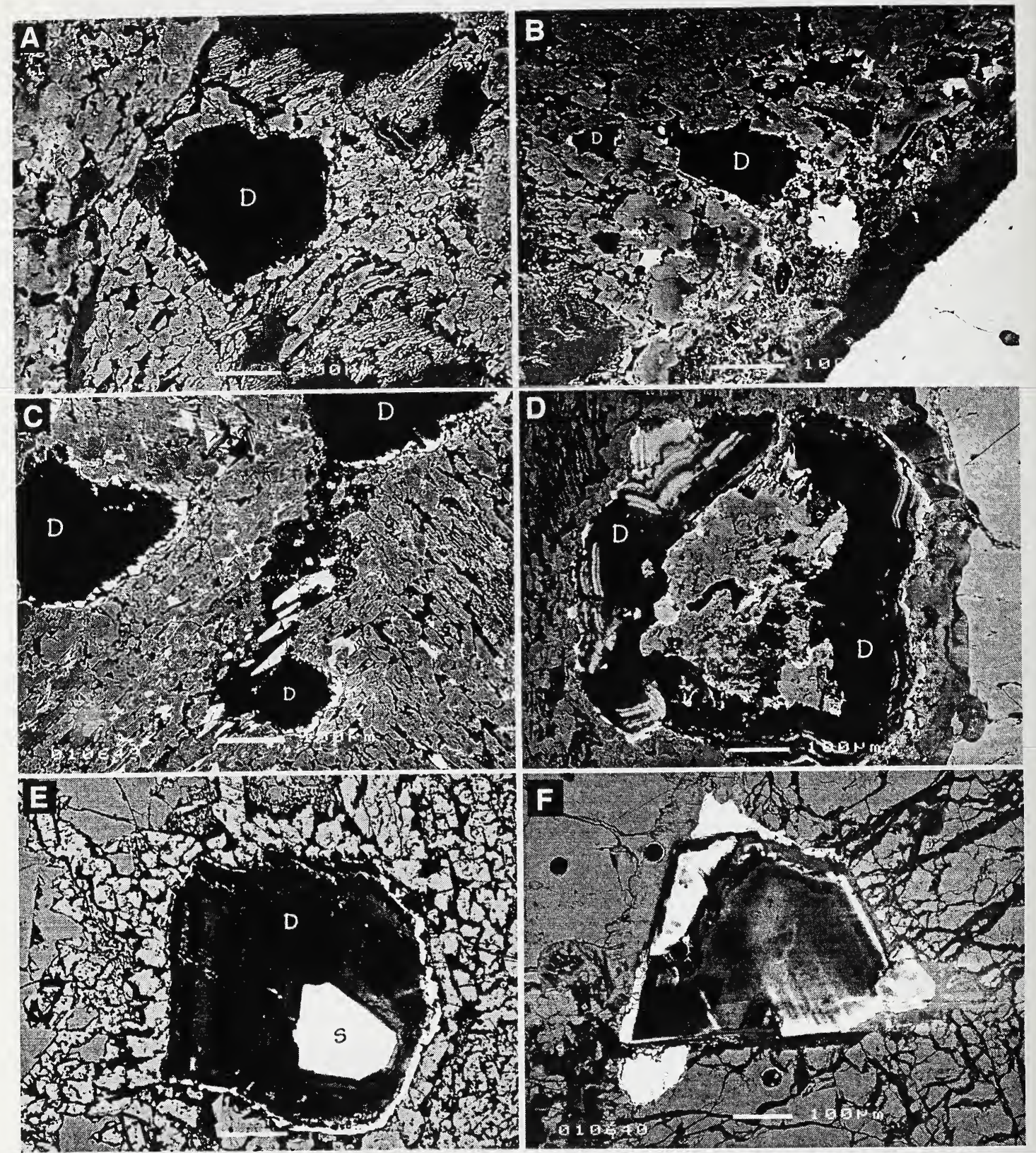

Figure 1. (a) diamond in recrystallized clinopyroxene (at top right is a primary $\mathrm{cpx}$ relict), sample Ud-189, BSE, (b) two diamond crystals in products of partial melting (Px+Sp+glass), Gt with kelyphite on bottom right, sample Ud-24, BSE+CL. (c) three slightly zoned diamonds in partial melting products, extend needles of highsodium pyroxene are present between two diamonds, sample Ud-24,BSE+CL. (d) zoned crystal of hopper diamond with captured secondary phases, sample Ud-45, BSE+CL.

(e) zoned diamond in recrystallized pyroxene with glass, sample Ud-28, BSE+CL.

(f) zoned diamond in partly recrystallized clinopyroxene, surrounded by vein secondary

pyroxene and sulfide, sample U-759, BSE+CL. All scale bars $=100$ microns 